\title{
A VERMICOMPOSTAGEM DO LODO DE LAGOAS DE TRATAMENTO DE EFLUENTES INDUSTRIAIS CONSORCIADA COM COMPOSTO DE LIXO URBANO
}

\section{THE VERMICOMPOSTING OF AN INDUSTRIAL SLUDGE COMBINED WITH A COMPOST OF MUNICIPAL SOLID REFUSE}

\begin{abstract}
LUCIANA RODRIGUES VALADARES VERAS
Doutora em Hidráulica e Saneamento pela Escola de Engenharia de São Carlos - USP. Professora Adjunta do Curso de Engenharia Civil da Universidade Presbiteriana Mackenzie
\end{abstract}

\author{
JURANDYR POVINELLI
}

Professor da Escola de Engenharia de São Carlos - Universidade de São Paulo Departamento de Hidráulica e Saneamento

Recebido: 15/10/03 Aceito: 27/05/04

\section{RESUMO}

A destinação dos resíduos sólidos constitui um sério problema ambiental para a humanidade, principalmente em regiōes de grande concentração urbana, onde a disponibilidade de áreas para disposição dos rejeitos é quase sempre restrita. Com a intenção de fornecer mais uma alternativa para solução do problema, desenvolveu-se um estudo para avaliar a vermicompostagem de um lodo industrial, resultante do processamento de frutas, consorciado com composto de lixo urbano. Através desse processo, pode-se obter a reciclagem dos resíduos, produzindo-se um composto denominado húmus ou vermicomposto. Dentre os resultados obtidos pode-se destacar bons indicadores do nível de maturidade dos resíduos, representados pela relação carbono/ nitrogênio, a influência da minhoca na elevação do $\mathrm{pH}$ e sua contribuição para uma estabilização mais acelerada da matéria orgânica.

PALAVRAS-CHAVE: Vermicompostagem, compostagem, lixo.

\begin{abstract}
The final disposal of solid wastes is a serious environmental problem, mainly in big towns, where the areas to put the refuses on are not much available. To provide one more alternative to solve this problem, a research was developed to analyse the vermicomposting of industrial sludge combined with a compost of municipal solid refuse. By this process, it was possible to obtain the recycling of the wastes, producing a material called humus or vermicompost. The results showed good maturity levels of the refuses, presented by the carbon/nitrogen relations, the worms influence in the $\mathrm{pH}$ elevation and their possible acceleration of the organic material stabilization.
\end{abstract}

\section{INTRODUÇÃO}

Os resíduos sólidos constituem hoje um dos principais problemas enfrentados pela humanidade. O acentuado crescimento demográfico seguido do grande desenvolvimento tecnológico vem aumentando consideravelmente a quantidade de resíduos sólidos refugados pelo homem, problemática que assume proporçōes ainda maiores, na medida em que se verifica a redução da disponibilidade de áreas para disposição dos rejeitos e o seu alto potencial de contaminação do meio ambiente.

$\mathrm{Na}$ tentativa de equacionar esse problema, vários métodos de tratamento e disposição foram e vêm sendo pesquisados em todo mundo, destacan- do-se os aterros sanitários, a compostagem, a incineração, a solidificação, entre outros.

De acordo com Metcalf \& Eddy (1991), a compostagem constitui alternativa econômica e ambientalmente correta para a estabilização de resíduos orgânicos industriais e de estaçôes de tratamento, com possibilidade de aproveitamento agronômico de tais resíduos.

Pereira Neto e Lelis (1999) afirmam que o grau de qualidade do composto orgânico indicará seu uso mais apropriado. Segundo eles, por pior que seja o produto, sempre estará inerte, não produzirá gases nem chorume e propiciará o crescimento de vegetais em áreas contaminadas, solos estéreis, voçorocas e aterros.
Essa tecnologia compreende a transformação de resíduos orgânicos em adubo humificado através de duas fases distintas: a primeira, quando ocorrem as reações bioquímicas de oxidação mais intensas e a segunda, quando ocorre o processo de humificação - fase de maturação.

Sendo desenvolvida por uma colônia de microrganismos, a compostagem é afetada por qualquer fator que atinja a atividade microbiológica. Dentre esses fatores, os mais importantes são: a aeração, a temperatura, o teor de umidade e a concentração de nutrientes.

Uma variante da tecnologia de compostagem é denominada vermicompostagem. Nela são utilizadas minhocas para produção do composto orgânico 
(vermicomposto), constituído pela mistura de matéria orgânica humificada e excrementos de minhocas. Estas por sua vez, têm participação decisiva na preservação de solos ainda em boas condições biológicas, ou mesmo na regeneração de terrenos empobrecidos pelo uso contínuo de agrotóxicos e adubos químicos. Sua intervenção é necessária para a formação do húmus natural, que é o componente principal das terras férteis.

A vermicompostagem é um processo constituído por dois estágios: no primeiro, a matéria orgânica é compostada segundo os métodos tradicionais de compostagem, proporcionando a redução de microrganismos patogênicos. Após aproximadamente 30 dias, segundo Bidone (2001), o composto é transferido para leitos rasos para não se aquecer demasiadamente e não se compactar, pois os materiais de granulometria fina têm essa tendência. Faz-se, então, a inoculação das minhocas e, 60 a 90 dias após, obtém-se o vermicomposto pronto, com aumento da disponibilidade de macro e micronutrientes e a formação de um húmus mais estável.

Edwards (1995) relata que os sistemas de vermicompostagem devem ser mantidos em temperaturas abaixo de $35^{\circ} \mathrm{C}$, já que a exposição da minhoca sob temperaturas acima desse valor, mesmo em curtos intervalos de tempo, provoca sua morte. As minhocas vivem ativamente numa estreita camada abaixo da superfície, sendo necessário, de acordo com o autor, a adição sucessiva de finas camadas de material orgânico (a cada um ou dois dias), para que o calor não se torne excessivo.

Fernandes \& Silva (1999) ressaltam que o composto não deve ser visto como um substituto do adubo mineral, mas como um condicionador de solos, cujo uso permite melhorar suas condiçôes gerais em longo prazo, fazendo com que as plantas aproveitem melhor o adubo mineral incorporado.

\section{METODOLOGIA}

Esse trabalho foi realizado na Estação Experimental do Departamento de Hidráulica e Saneamento, da Escola de Engenharia de São Carlos, Universidade de São Paulo. Para tanto, utilizou-se lodo da lagoa anaeróbia da Citrosuco Paulista S.A. de Matão - SP, que foi vermicompostado com o auxílio do substrato orgânico (composto orgânico do lixo urbano) proveniente da Estação Experimental da CETESB, em Novo Horizonte - SP.
Os dois materiais foram colocados em camadas de aproximadamente $5 \mathrm{~cm}$ sobre sacos plásticos estendidos no chão, para secagem ao ar livre. Em seguida, foram passados em peneira de $8 \mathrm{~mm}$, para maior uniformização do tamanho das partículas e para que fossem eliminados materiais indesejáveis ao bom desempenho do processo.

Cinco caixas de compensado naval, denominadas de leiras de vermicompostagem, foram dispostas sobre uma mesa de madeira de 0,80 metro de altura. Essas leiras tinham, cada uma, $0,51 \mathrm{~m}$ de largura, 0,54 $\mathrm{m}$ de comprimento e $0,50 \mathrm{~m}$ de altura. Ao mesmo tempo, 5 vasos cerâmicos (tronco cone) com altura de $0,30 \mathrm{~m}$, diâmetro inferior de $0,20 \mathrm{~m}$ e superior de $0,35 \mathrm{~m}$ foram dispostos no chão, em lugar coberto, para o recebimento do mesmo material das leiras, porém sem a presença de minhocas.

Em seguida foram adicionadas quantidades do composto orgânico e do lodo, nas leiras e nos vasos, nas seguintes proporções:

- leira 1, vaso 1 - 100\% de composto;

- leira 2, vaso 2 - 75\% de composto e 25\% de lodo;

- leira 3, vaso 3 - 50\% de composto e 50\% de lodo;

- leira 4, vaso 4 - 25\% de composto e 75\% de lodo;

- leira 5, vaso 5 - 100\% de lodo.

Concluída a etapa de montagem, adicionou-se água até que o teor de umidade atingisse o intervalo entre 35 a $40 \%$.

Sete dias depois foram retiradas amostras em três diferentes pontos de cada leira, ao longo de toda a altura, com o auxílio de um cilindro, a fim de se obter a análise do material no início do processo (antes da inoculação das minhocas).

Iniciou-se então a inoculação da minhoca Eisenia foetida, com aplicação de aproximadamente 500 indivíduos por leira. A escolha por essa espécie de minhoca deveu-se ao fato desses indivíduos apresentarem alta capacidade reprodutiva e preferência por ambientes com elevado conteúdo de matéria orgânica.

Decorrido um intervalo de 75 dias após a inoculação, iniciou-se então a coleta do vermicomposto e do material contido nos vasos, para análise dos seguintes parâmetros, de acordo com procedimentos descritos em Kiehl (1985): pH, matéria orgânica total, carbono total, nitrogênio total, fósforo, potássio, cálcio, magnésio e relação carbono/nitrogênio $(\mathrm{C} / \mathrm{N})$. O mesmo procedimento, relata- do anteriormente em relação à amostragem, foi repetido nessa fase, após a homogeneização do material.

Análises estatísticas dos resultados foram efetuadas considerando-se as diferenças obtidas nas mediçôes antes e depois da vermicompostagem. O experimento foi constituído de 10 tratamentos para cada variável (5 caixas, presença/ausência de minhocas), sendo registradas 3 observaçôes em cada tratamento. Desta forma, cada uma das variáveis estudadas apresentou um conjunto de 30 observações ( 5 caixas, presença/ausência de minhocas, 3 repetiçōes). A análise de variância a três fatores, "ANOVA-three-way", descrita por Neter; Wasserman e Kutner (1990), foi empregada no estudo estatístico dos dados. Essa técnica consiste em testar os efeitos principais dos fatores e o efeito da interação entre os mesmos, conforme Tabela 1.

Na Tabela 1, os quadrados médios (QM) foram obtidos dividindo-se as somas dos quadrados (SM) pelos respectivos graus de liberdade. Através da comparação dos valores de $F$, obtidos na análise de variância, com valores tabelados, pode-se detectar a ocorrência do efeito do tratamento.

Para os casos em que as condições de utilização da técnica "ANOVA-three-way" não foram satisfeitas, recorreu-se a métodos não paramétricos, descritos em Lehmann e D'Abrera (1975). Os fatores minhoca, caixa e tempo foram então combinados em um único fator com 20 níveis, conforme demonstra a Tabela 2 .

As hipóteses checadas nesse teste foram $\mathrm{H}_{0}$ (não houve diferença entre os tratamentos) versus $\mathrm{H}_{1}$ (pelo menos um dos tratamentos foi diferente). No caso de rejeição de $\mathrm{H}_{0}$, a análise prosseguiu com a aplicação do teste de comparações múltiplas entre os 20 tratamentos, ordenando-os em seguida de acordo com as hipóteses $\mathrm{H}_{0}$ (não houve diferença entre os tratamentos) versus $\mathrm{H}_{1}$ (o tratamento $B$ é superior ao tratamento $A$ ).

\section{RESULTADOS E DISCUSSÕES}

Na Tabela 3 encontram-se os resultados dos teores de umidade referentes a cada leira, durante a realização da parte experimental do trabalho. Como se pode observar, os valores foram controlados de forma a serem mantidos em torno de 45\%. Esse controle também foi efetuado no caso dos vasos. A opção por esse valor deveu-se à perda de água através do fundo das leiras e vasos à medida que se au- 
Tabela I - Análise de variância a três fatores - "ANOVA-three-way"

\begin{tabular}{ccccc}
\hline Fonte de variação & $\begin{array}{c}\text { Graus de } \\
\text { liberdade }\end{array}$ & $\begin{array}{c}\text { Soma dos } \\
\text { quadrados }(\mathrm{SQ})\end{array}$ & $\begin{array}{c}\text { Quadrados } \\
\text { médios }(\mathrm{QM})\end{array}$ & $\mathrm{F}^{*}$ \\
\hline Fator Caixa (A) & 4 & $\mathrm{SQA}$ & $\mathrm{QMA}$ & $\mathrm{F}_{\mathrm{A}}=\mathrm{QMA} / \mathrm{QME}$ \\
Fator Minhoca (B) & 1 & $\mathrm{SQB}$ & $\mathrm{QMB}$ & $\mathrm{F}_{\mathrm{B}}=\mathrm{QMB} / \mathrm{QME}$ \\
Fator Tempo (C) & 1 & $\mathrm{SQC}$ & $\mathrm{QMC}$ & $\mathrm{F}_{\mathrm{C}}=\mathrm{QMC} / \mathrm{QME}$ \\
Interação caixa*minhoca (AB) & 4 & $\mathrm{SQAB}$ & $\mathrm{QMAB}$ & $\mathrm{F}_{\mathrm{AB}}=\mathrm{QMAB} / \mathrm{QME}$ \\
Interação caixa*tempo (AC) & 4 & $\mathrm{SQAC}$ & $\mathrm{QMAC}$ & $\mathrm{F}_{\mathrm{AC}}=\mathrm{QMAC} / \mathrm{QME}$ \\
Interação tempo*minhoca (BC) & 1 & $\mathrm{SQBC}$ & $\mathrm{QMBC}$ & $\mathrm{F}_{\mathrm{BC}}=\mathrm{QMBC} / \mathrm{QME}$ \\
Interação caixa*tempo*minhoca $(\mathrm{ABC})$ & 4 & $\mathrm{SQABC}$ & $\mathrm{QMABC}$ & $\mathrm{F}_{\mathrm{ABC}}=\mathrm{QMABC} / \mathrm{QME}$ \\
Erro $(\mathrm{E})$ & 40 & $\mathrm{SQE}$ & $\mathrm{QME}$ & \\
Total & 59 & $\mathrm{SQT}$ & & \\
\hline
\end{tabular}

Tabela 2 -Análise não-paramétrica

\begin{tabular}{|c|c|c|c|}
\hline Leira & Minhoca & Tempo & Tratamento \\
\hline 1 & presença & 0 & 1 \\
\hline 2 & presença & 0 & 2 \\
\hline 3 & presença & 0 & 3 \\
\hline 4 & presença & 0 & 4 \\
\hline 5 & presença & 0 & 5 \\
\hline 1 & ausência & 0 & 6 \\
\hline 2 & ausência & 0 & 7 \\
\hline 3 & ausência & 0 & 8 \\
\hline 4 & ausência & 0 & 9 \\
\hline 5 & ausência & 0 & 10 \\
\hline 1 & presença & 1 & 11 \\
\hline 2 & presença & 1 & 12 \\
\hline 3 & presença & 1 & 13 \\
\hline 4 & presença & 1 & 14 \\
\hline 5 & presença & 1 & 15 \\
\hline 1 & ausência & 1 & 16 \\
\hline 2 & ausência & 1 & 17 \\
\hline 3 & ausência & 1 & 18 \\
\hline 4 & ausência & 1 & 19 \\
\hline 5 & ausência & 1 & 20 \\
\hline
\end{tabular}


mentava o teor de umidade. Esse fato possivelmente alteraria a composição química do material a ser analisado, já que a água arrastaria consigo parte dos elementos químicos presentes na mistura lodo/composto. Lelis et al. (1999) observaram que a manutenção do teor de umidade na faixa entre 45 e $55 \%$ proporciona a maximização da velocidade de degradação, a redução dos impactos ambientais associados ao processo e a eliminação dos organismos patógenos.

Independentemente do tempo de vermicompostagem, notou-se que quanto maior a proporção de composto em relação ao lodo, maior o percentual de matéria orgânica na mistura (Figura 1). Esse resultado já era esperado, visto que as características naturais do composto apresentam conteúdo de material orgânico superior ao do resíduo industrial $(21,87 \%$ e $12,75 \%$, respectivamente - Tabelas 4 e 5).

As Figuras 1 a 9, mostram as médias dos 3 valores observados para cada parâmetro no início do experimento (quando o material contido no vaso e nas leiras era o mesmo) e no final do experimento (material na presença de minhocas, no caso das leiras, e na ausência de minhocas, para o caso dos vasos).

Outro fato a ser destacado consiste na proliferação das minhocas na vermicompostagem. Ao final do processo, o número de indivíduos nas leiras 1, 2 e 3 foi maior em relação as demais caixas, indicando mais uma vez, a presença de alto teor de matéria orgânica contido nesses casos.

Para o experimento em questão, não foi verificado o efeito da minhoca sobre o parâmetro analisado (matéria orgânica), de acordo com a análise estatística dos dados, confirmando os resultados obtidos por Bidone (1995).

Com relação ao teor de carbono presente nas diversas composições (Figura 2), era esperado comportamento semelhante ao da matéria orgânica, já que seu valor foi obtido dividindo-se a matéria orgânica total por 1,8.

Não foi observada, em nenhuma leira, diferença significativa do percentual de matéria orgânica e consequentemente de carbono para o início e final do experimento.

Bidone (1995) também verificou em sua pesquisa que, em leiras onde predominou o composto de lixo urbano

Tabela 3 - Teor de umidade nas leiras de vermicompostagem

\begin{tabular}{ccccc}
\hline Leira 1 & Leira 2 & Leira 3 & Leira 4 & Leira 5 \\
\hline 46,5 & 44,5 & 47,0 & 49,5 & 49,0 \\
38,5 & 40,0 & 44,0 & 47,0 & 50,0 \\
44,0 & 46,5 & 50,0 & 40,3 & 52,8 \\
42,8 & 45,0 & 46,5 & 47,0 & 46,5 \\
46,8 & 45,8 & 45,0 & 49,0 & 49,0 \\
42,8 & 42,5 & 41,0 & 47,5 & 48,0 \\
44,0 & 43,5 & 43,0 & 46,5 & 47,0 \\
\hline
\end{tabular}

Tabela 4 - Caracterização química do composto de lixo urbano

\begin{tabular}{|c|c|c|c|c|}
\hline Variável & $1^{\mathrm{o}}$ valor & $2^{\mathrm{o}}$ valor & $3^{\text {o }}$ valor & Média \\
\hline $\mathrm{pH}$ & 6,9 & 6,9 & 6,8 & 6,9 \\
\hline Matéria orgânica (\%) & 23,40 & 22,12 & 20,09 & 21,87 \\
\hline Carbono (\%) & 13,00 & 12,29 & 11,17 & 12,15 \\
\hline Nitrogênio (\%) & 1,10 & 1,08 & 1,87 & 1,35 \\
\hline Fósforo (\%) & 0,66 & 0,49 & 0,41 & 0,52 \\
\hline Potássio (\%) & 0,34 & 0,31 & 0,29 & 0,31 \\
\hline Cálcio (\%) & 1,16 & 0,97 & 0,64 & 0,92 \\
\hline Magnésio (\%) & 0,19 & 0,16 & 0,15 & 0,17 \\
\hline Relação C/N & $12 / 1$ & $11 / 1$ & $13 / 1$ & $12 / 1$ \\
\hline$(\%)$ & $1^{\mathrm{o}}$ valor & $2^{\circ}$ valor & $3^{\circ}$ valor & média \\
\hline $\mathrm{pH}$ & 6,6 & 6,7 & 6,6 & 6,6 \\
\hline Matéria orgânica (\%) & 12,69 & 12,28 & 13,27 & 12,75 \\
\hline Carbono (\%) & 7,05 & 6,82 & 7,38 & 7,08 \\
\hline Nitrogênio (\%) & 0,72 & 0,73 & 0,79 & 0,75 \\
\hline Fósforo (\%) & 0,31 & 0,39 & 0,41 & 0,37 \\
\hline Potássio (\%) & 0,04 & 0,04 & 0,04 & 0,04 \\
\hline Cálcio (\%) & 26,20 & 27,33 & 27,01 & 26,85 \\
\hline Magnésio (\%) & 0,10 & 0,10 & 0,10 & 0,10 \\
\hline Relação C/N & $10 / 1$ & $9 / 1$ & $9 / 1$ & $9 / 1$ \\
\hline
\end{tabular}

como substrato, a quantidade de matéria orgânica foi estatisticamente igual, para o inícioe final do processo.

Os resultados obtidos com relação ao nitrogênio (Figura 3) revelaram que quanto maior a proporção de composto, maior o seu percentual e que os valores médios desse parâmetro diminuíram na leira 1, com presenca de minhoca. Para as demais leiras não houve a influência da minhoca, sendo que o teor desse elemento aumentou no final do processo.

Segundo Kiehl (1985), os resíduos orgânicos a serem compostados têm, ge- 


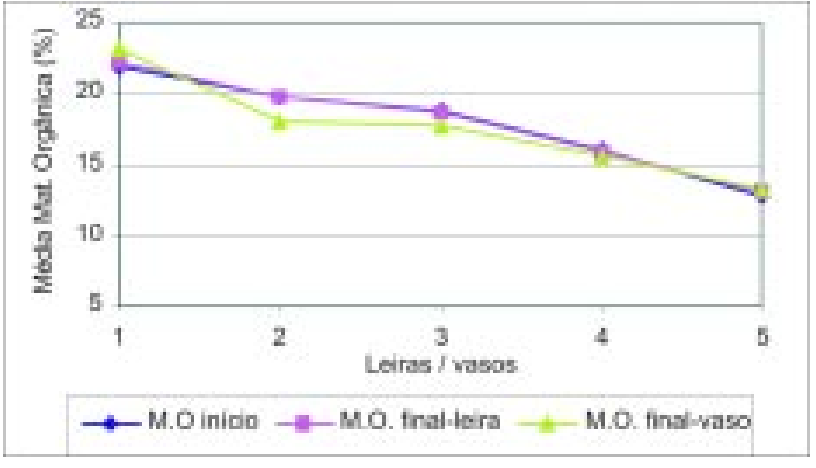

Figura I - Média dos valores de matéria orgânica nas leiras e vasos, para início e final do experimento

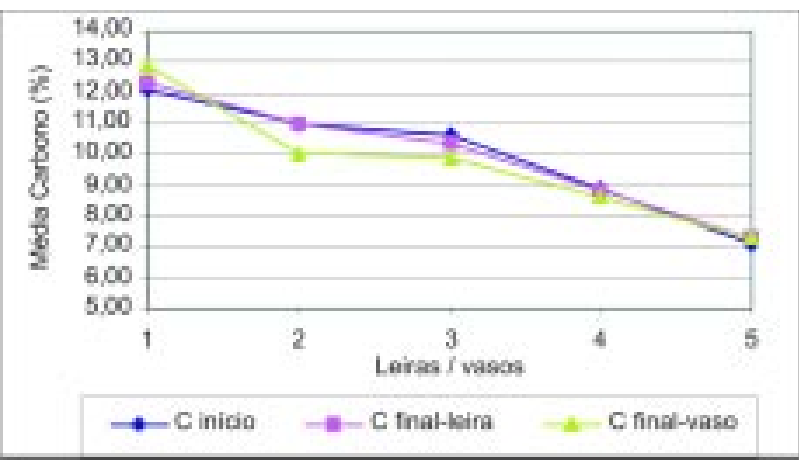

Figura 2 - Média dos valores de carbono total nas leiras e vasos, para início e final do experimento

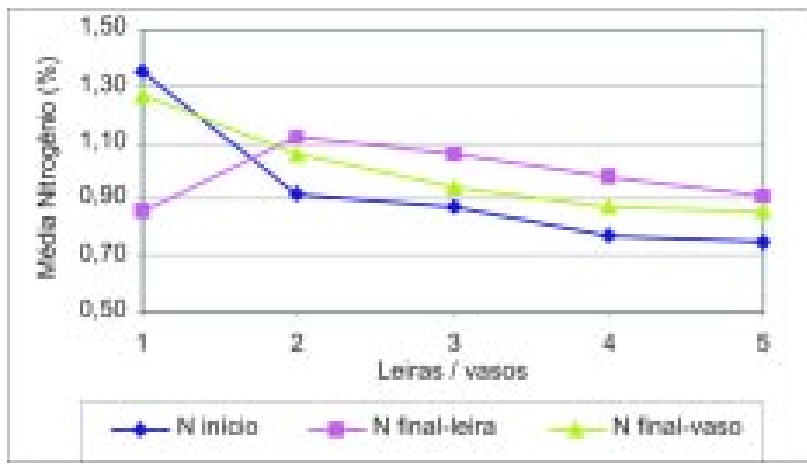

Figura 3 - Média dos valores de nitrogênio total nas leiras e vasos, para início e final do experimento ralmente, maior proporção de nitrogênio do que de fósforo e potássio, o que confirma os valores obtidos nessa pesquisa. Dentre esses três nutrientes, o nitrogênio é o que apresenta maior variabilidade em seu conteúdo e o que menos se conserva no solo, sendo também o elemento que mais facilmente se perde por volatilização ou lavagem.

Os principais fatores na compostagem aeróbia que podem ter levado à perda de nitrogênio na leira 1 foram os seguintes: relação $\mathrm{C} / \mathrm{N}$ e conteúdo de umidade. É possível haver perda de nitrogênio se a matéria-prima utilizada no preparo do composto tiver baixa relaçáo $\mathrm{C} / \mathrm{N}$. No presente trabalho, a perda desse elemento nessa leira pode ser atribuída a esse fato, visto que os valores iniciais de $\mathrm{C} / \mathrm{N}$ giraram em torno de 12/1.

Outro fato a se considerar é o teor de umidade verificado nessa leira, com menor média entre todas, proporcionando a perda de nitrogênio. A presença de água ajuda na retenção da amônia $\left(\mathrm{NH}_{3}\right)$, pois esse gás, combinando-se com a água, produz o elemento químico hidróxido de amônio ou amoníaco $\left(\mathrm{NH}_{3}+\mathrm{HOH} \leftrightarrow \mathrm{NH}_{4} \mathrm{OH}\right)$. Para teores de umidade menores $\mathrm{a} 40 \%$ pode haverperdadeamônia no meio(Bidone, 1995).
A influência da minhoca na leira 1 , diminuindo do teor de nitrogênio, pode não ser um fator conclusivo para esse caso, devido às possibilidades de perda desse elemento descritas acima.

$\mathrm{O}$ aumento do teor desse nutriente ao final do experimento, sem que houvesse a influência da minhoca, pode ser atribuído à possibilidade de ocorrer adição através da fixação do nitrogênio atmosférico, contido no interior do monte do composto, ou seja, através da conversão do $\mathrm{N}_{2}$ gasoso em compostos utilizáveis pelas plantas, feita por certas espécies de organismos altamente especializados. A fixação desse nutriente por organismos especializados se dá principalmente quando o composto está curado, quase seco e não contém nitrogênio amoniacal.

Foi também constatado nesta pesquisa que o teor de cálcio era tanto maior quanto maior a proporção de resíduo industrial nas leiras (Figura 4). Esse fato deve ter ocorrido em razão das altas concentraçôes desse elemento no lodo, conforme caracterização fornecida pela indústria.

Outro resultado obtido diz respeito ao aumento da concentração de cálcio nos tratamentos com minhoca e também naqueles em que não houve a inoculação dessa espécie. Esse resultado contraria a literatura consultada, uma vez que as análises realizadas em laboratório fornecem o conteúdo de cálcio total e não de cálcio disponível. Segundo Bidone (2001) a minhoca não aumenta o teor de nutrientes no húmus, mas sim, aumenta sua disponibilidade, que da forma orgânica bruta, indisponível para as plantas tornamse solúveis e facilmente assimiláveis pelas raízes. O húmus, através de reações de troca ou mecanismos de quelação, pode reter nutrientes liberados da matéria orgânica. O fenômeno de formação do

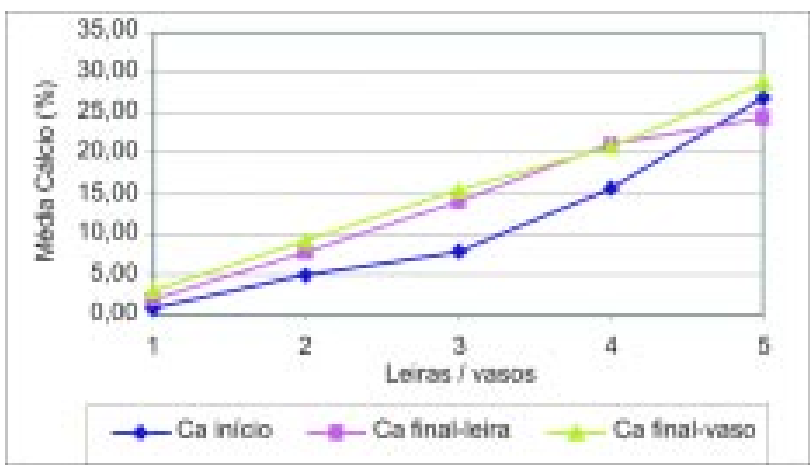

Figura 4 - Média dos valores de cálcio nas leiras e vasos, para início e final do experimento 
tal, é razoável admitir que tal incremento se deu pela redução do volume nas leiras e conseqüente aumento da porcentagem de cálcio no meio. Essa redução decorrente do processo de compostagem pode atingir até um terço do volume inicial.

Como mencionado anteriormente, a relação $\mathrm{C} / \mathrm{N}$ apresentou-se bastante homogênea no início do processo de vermicompostagem, com valores em torno de 12/1 (Figura 5).

Jiménez et al. (1992) concluem, após terem realizado um estudo para avaliar os melhores parâmetros indicadores do grau de maturidade de um composto de resíduo urbano, que uma relação $\mathrm{C} / \mathrm{N}$ menor que 12 é mais apropriada para assegurar um bom nível de maturidade, comparado com os valores comumente aceitáveis de $\mathrm{C} / \mathrm{N}$ menores que 20. Entretanto, esse parâmetro não pode ser considerado como um indicador suficiente do grau de maturidade para a matériaprima. Com base nesses dados, pode-se admitir que os valores finais desse trabalho são bons indicadores do nível de maturidade dos resíduos.

Constatou-se o aumento do $\mathrm{pH}$ ao longo do período de 75 dias em praticamente todas as leiras (Figura 6). Apenas os vasos 3 e 4 apresentaram diminuição significativa do parâmetro ao final do experimento. Esses resultados sugerem a participação da minhoca na elevação do $\mathrm{pH}$ dos ambientes onde ocorreram a vermicompostagem. Segundo Bidone (1985), do esôfago das minhocas saem pequenas bolsas, as glândulas calcíferas, que segregam carbonato de cálcio, controlando o teor desse elemento no organismo do animal. $\mathrm{O} \mathrm{CO}_{2}$ produzido pela respiração é eliminado com o excesso de cálcio absorvido do solo, formando o $\mathrm{CaCO}_{3}$, que é lançado ao exterior junto com partículas não digeridas, na forma de excrementos. Assim, as constantes adições de carbonato de cálcio contribuem para o aumento do $\mathrm{pH}$, explicando os incrementos observados no presente experimento.

Bidone (2001) afirma que a compostagem aeróbia provoca elevação do $\mathrm{pH}$. Esta afirmação está de acordo com os resultados obtidos nos vasos onde não ocorreu inoculação de minhocas, mas houve aumento do $\mathrm{pH}$.

Por outro lado, Albanell et al. (1988) atribuem a diminuição do $\mathrm{pH}$ à produção de $\mathrm{CO}_{2}$ e de ácidos orgânicos durante o metabolismo dos microrganismos presentes no processo de compostagem. Esse fenômeno pode ter ocorrido nos vasos $3 \mathrm{e} 4$.

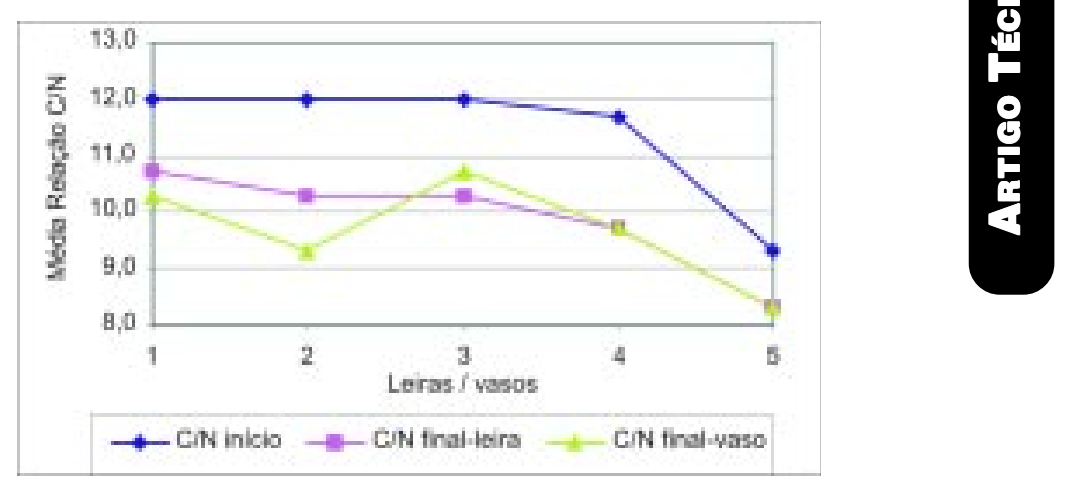

Figura 5 - Média das relações carbono/nitrogênio nas leiras e vasos, para início e final do experimento

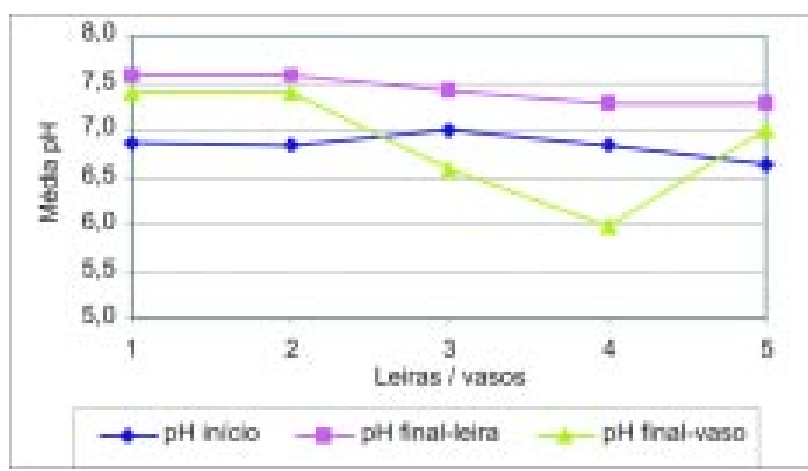

Figura 6 - Média de pH nas leiras e vasos, para início e final do experimento

Pode-se constatar na Figura 7 que no início do experimento, quando não havia presença de minhoca, o teor de magnésio era tanto maior quanto a proporção de composto em relação ao resíduo industrial. Conforme mencionado anteriormente, a quantidade de matéria orgânica no composto é superior a do resíduo, explicando assim a presença mais marcante de magnésio nas primeiras leiras, resultante da contribuição dada pelo material orgânico, ainda que em pequena proporção.

Com relação às leiras 3,4 e 5, que apresentaram maiores concentraçóes de magnésio nos tratamentos com minhoca, pode-se dizer que esse acréscimo ocorreu graças à redução de volume provocada pelo processo de vermicompostagem. Foi notório em praticamente todos os casos que essa redução foi mais acentuada nas leiras do que nos vasos. De acordo com Longo (1992), a presença desses indivíduos acelera a estabilização do material a ser compostado, transformando mais rapidamente as substâncias orgânicas em compostos estáveis.

Nos vasos, o percentual de fósforo sofreu um incremento com o tempo e nas leiras, o conteúdo desse elemento diminuiu em quase todos os casos, ao final do período (Figura 8 ). O incremento de fósforo observado deveu-se provavelmente à redução do volume resultante do processo de compostagem. Nos casos dos tratamentos com minhoca, onde houve diminuições dos teores de fósforo, pode-se admitir que as elas tenham imobilizado esse nutriente, ou seja, esses indivíduos possivelmente absorveram, durante seu metabolismo, parte do conteúdo presente nas leiras.

Os valores de potássio foram maiores conforme a proporção de composto se elevou (Figura 9). O potássio encontra-se no solo adsorvido eletrostaticamente à matéria orgânica e inor gânica ou como constituinte dos resíduos orgânicos e dos microrganismos vivos. Sendo assim é razoável dizer que quanto maior o conteúdo de matéria orgânica na mistura lodo/composto, maior o teor de potássio encontrado. Nesse caso, não houve diferença significativa entre os resultados observados para o início e final do experimento.

\section{CONCLUSÕES}

Os resultados obtidos no processo de vermicompostagem permitiram chegar às principais conclusóes: 


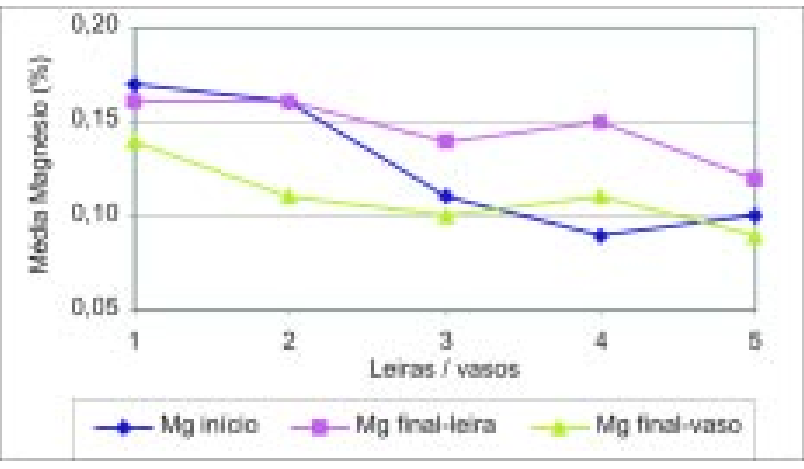

Figura 7 - Média dos valores de magnésio nas leiras e vasos, para início e final do experimento

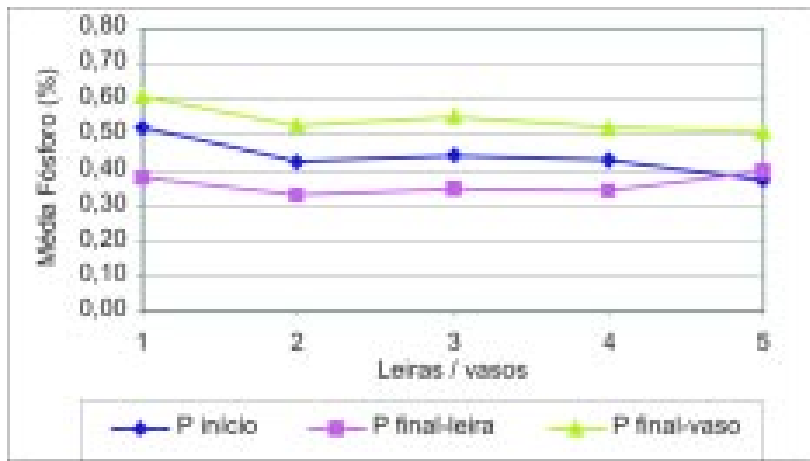

Figura 8 - Média dos valores de fósforo total nas leiras e vasos, para início e final do experimento

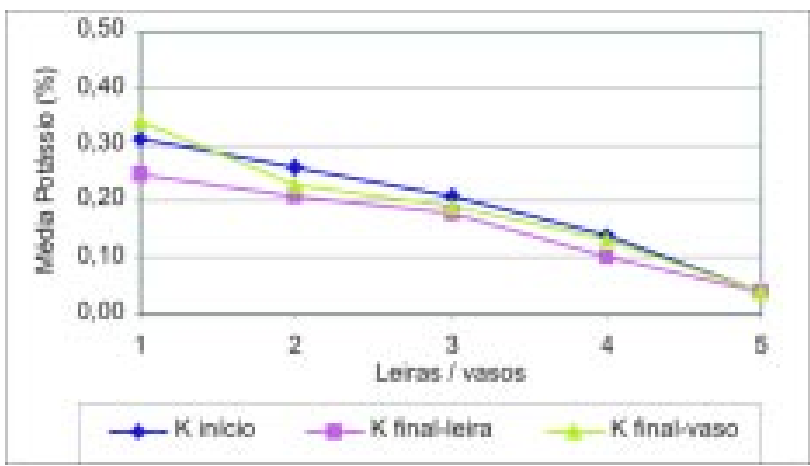

Figura 9 - Média dos valores de potássio nas leiras e vasos, para início e final do experimento

1. O aumento do teor de nitrogênio ao final do experimento, sem que houvesse a influência da minhoca, pode ser devido à adição do nitrogênio atmosférico, contido no interior das leiras.

2. Os valores finais das relações carbono/nitrogênio nesse trabalho podem ser bons indicadores do nível de maturidade dos resíduos.

3. Os aumentos verificados nas concentrações de cálcio, magnésio e fósforo ocorreram provavelmente graças à redução de volume resultante do processo de vermicompostagem.

\section{REFERÊNCIAS}

ALBANELL, E. et al. Chemical changes during vermicomposting (Eiseinia foetida) of sheep manure mixed cotton industrial wastes. Biology and Fertility of Soils. p. 266-269. 1988.

BIDONE, F. R. A. A Vermicompostagem dos Resíduos Sólidos de Curtume, Brutos e Previamente Lixiviados, Utilizando Composto de Lixo Orgânico Urbano como Substrato. São Carlos, 184p. Tese de Doutorado - Escola de Engenharia de São Carlos, Universidade de São Paulo. 1995 .

BIDONE, F. R. A. (coord.) Resíduos Sólidos Provenientes de Coletas Especiais: Eliminação e Valorização. Rio de Janeiro, ABES, 218 p. 2001.

EDWARDS, C. A. Historical Overview of Vermicomposting. BioCycle, p. 56-58, jun. 1995

FERNANDES, F.; SILVA, S.M.C. Manual prático para compostagem de biossólidos. São Paulo, 84p. 1999

JIMÉNEZ, E.I. e GARCIA, V.P. Determination of Maturity Indices for City Refuse Composts. Agriculture Ecosystems and Environment, v.38, p.331-343.1992.

KIEHL,E.J. Fertilizantes Orgânicos. São Paulo, Ed.Ceres, 458p. 1985

LEHMANN, E.L. e D'ABRERA, H.J.M. The comparison of more than two treatments. In: NONPARAMETRICS STATISTICAL METHODS BASED ON RANKS. San Francisco, p. 75-94. 1975.

LELIS, M.P.N et al. A influencia da umidade na velocidade de degradação e no controle de impactos ambientais da compostagem. In: $20^{\circ}$ CONGRESSO DA ABES. Rio de Janeiro, 10 p. 1999.

LONGO, A.D. Minhoca: de Fertilizadora do Solo a Fonte Alimentar. São Paulo, Ed. İcone, 79p. 1992.

METCALF e EDDY Design of Facilities for the Treatment and disposal of Shudge. In: WASTEWATER ENGENEERING- TREATEMENT, DISPOSAL AND REUSE. $3^{\text {rd }}$ ed. U.S.A. McGraw-Hill International Editions, p.765-926. 1991.

NETER, J.; WASSERMAN, W. and KUTNER, M. H. Applied Linear Statistical Models, 3rd Ed. USA, McGraw-Hill, 1181 p. 1990.

PEREIRA NETO, J.T.; LELIS, M. P. N. Importância da umidade na compostagem: uma contribuição ao estado da arte. In: $20^{\circ}$ CONGRESSO da ABES, Rio de Janeiro. 8p. 1999.

\section{Endereço para correspondência:}

Luciana Rodrigues Valadares Veras Universidade Presbiteriana Mackenzie Rua da Consolação, 896 - Prédio 6 0I302-907 - São Paulo - SP - Brasil Tel.: (II) 3236-8553

E-mail: lucianaveras@mackenzie.com.br 